Research Article

\title{
Experimental Research on Mechanical Properties of High-Temperature Sandstone with Different Cooling Methods
}

\author{
Minglei Zhang $\mathbb{D}^{1},{ }^{1}$ Runde Qiu, ${ }^{1}$ Lei Yang, ${ }^{2}$ and Yuting Su ${ }^{1}$ \\ ${ }^{1}$ Institute of Disaster Prevention, Langfang 065201, China \\ ${ }^{2}$ Capital Construction Division, The Central Academy of Drama, Beijing 102209, China
}

Correspondence should be addressed to Minglei Zhang; zml@cidp.edu.cn

Received 27 May 2020; Revised 28 August 2020; Accepted 5 September 2020; Published 15 September 2020

Academic Editor: Hailing Kong

Copyright $(02020$ Minglei Zhang et al. This is an open access article distributed under the Creative Commons Attribution License, which permits unrestricted use, distribution, and reproduction in any medium, provided the original work is properly cited.

Various tests including the longitudinal wave velocity tests and uniaxial compression tests have been conducted to evaluate the impact of cooling methods (including natural cooling, water cooling, and cooling by liquid carbon dioxide) on mechanical properties of sandstone under the natural status and high temperature. The acoustic emission signals were also monitored during the tests. According to the tests conducted, the sandstone sample density attenuation rate and the longitudinal wave velocity attenuation rate are higher than those of the specimen under natural status while the uniaxial compressive strength and Young's modulus are lower. Comparing with the sandstone under the natural status, the compression sections of the stress-strain curves of the high-temperature sandstone samples treated by three cooling methods are longer with lower strain peak values. The order of the acoustic emission is revealed as follows: the sample cooled by liquid carbon dioxide $<$ the sample cooled by water $<$ sample cooled naturally<the sample under natural status, which suggests that the rapid cooling (cooled by liquid carbon dioxide) produces the severest damage on the sample, followed by the water cooling and natural cooling methods. In addition, the relationship between the sample strength weakening coefficient and the cooling rate is defined based on the statistical data of the cooling time of the high-temperature specimen under the three cooling methods.

\section{Introduction}

Since the $21^{\text {st }}$ century, the rapid economic development of various countries has raised higher demands to the resource, energy, and space, resulting in outstanding problems such as environmental pollution on the ground, resource shortages, and traffic congestion, which poses as a serious threat to the social health and sustainable development. Exploring the underground space and resources hidden in the depths of the earth has become the trend of future development, leading to the booming development of underground projects. Many nations have initiated various underground space construction projects [1]. Fire is one of the common disasters troubling the underground space. The high temperature and cooling effect produced during the control of fire accidents tend to modify the physical and mechanical properties of underground engineering rock mass, jeopardizing the stability and service life of underground facilities. Common fire extinguishing methods include dry powder fire extinguishing, fire extinguishing blankets, water fire extinguishing, and liquid carbon dioxide fire extinguishing, and specific fire extinguishing methods are selected in various regions based on individual fire condition, technologies available, and local economy [2]. Various fire extinguishing methods produce different cooling rates, resulting in various levels of destructive effect on the high-temperature surrounding rock. As a result, disparities are often present in the damages of the surrounding rock mass in underground facilities. Unlike the ground construction, underground facilities are usually highly concealed, resulting in more maintenance difficulties and higher expenses [3-6]. Therefore, conducting research studies to evaluate the impact of different cooling methods on the mechanical properties of underground engineering rock mass after high temperature becomes necessary. 
In recent years, experts domestic and abroad have conducted a considerate number of research studies on the rock cooled after high temperature through laboratory tests and numerical simulations. Cooling methods for high-temperature rocks can be divided into the natural cooling, the water cooling, and the rapid cooling methods [7-9]. Regarding the natural cooling method, Yang et al. [10] analyzed the changes occurred to the shapes, compressive strengths, peak strains, and Young's modulus of high-temperature sandstone as well as the damage and deterioration mechanism of sandstone after the high temperature. Focusing on the tensile strength and size changes, Su et al. [11] studied the cooling impact on the red sandstone. Xu and Zhou [12] investigated the uniaxial compressive strengths of sandstone specimens under different high temperatures and obtained the temperature at the turning point of strength change trend. Zhao et al. [13] and Hou and Peng [14], respectively, studied the mechanical properties of granite and marble after high temperature, including the microscopic parameter analysis through the diffraction test and electron microscope scanning. In terms of the water cooling method, some scholars [15-18] analyzed the mechanical properties of high-temperature granite, marble, limestone, and sandstone after the water cooling, including the analysis of changes in uniaxial compressive strength, tensile strength, and Young's modulus. In terms of the rapid cooling (cooled by liquid carbon dioxide, liquid nitrogen, and calcium chloride solution), Han et al. [19], Jin et al. [20], Shen et al. [21-23], Isaka et al. [24], Hosseini [25], and Li et al. [26] studied the damage effect of granite cooled by the rapid method, including the analysis of changes in uniaxial compressive strength, tensile strength, Young's modulus, fluctuation characteristics, acoustic emission characteristics, and microscopic characteristics.

The existing research studies focus on the impact of the natural cooling and water cooling methods on the mechanic properties of sandstone. Limited studies have been conducted to evaluate the impact of rapid cooling (cooled by liquid carbon dioxide) and various cooling methods on the rock mechanical properties of the same type. During the fire accidents in the underground facilities, the surrounding rock is often heated continuously and experiences quick cooling during the fire rescue. Various extinguishing methods produce different cooling effects, resulting in different thermal shocks. The mechanical behaviors of rock change accordingly. Taking the engineering background aforementioned into consideration, the most common sandstone in the coal seam is selected as the research object. Sandstone specimens were cooled by three methods including the natural cooling, the water cooling, and the rapid cooling (cooled by liquid carbon dioxide). In addition, uniaxial compression strengths were tested with the cooling rate as the variable to explore the impact of cooling methods on mechanical properties of sandstone under high temperature.

\section{Test Overview}

The sandstone specimens originated from a coal mine located at Yang Quan, Shanxi province, with an average density of $2.4 \mathrm{~g} / \mathrm{cm}^{3}$. As shown in Figure 1, sandstones were processed into the standard cylinder specimen with a diameter of $50 \mathrm{~mm}$ and a height of $100 \mathrm{~mm}$. Minimum three specimens were prepared for each cooling method. An electronic scale with an accuracy of $0.01 \mathrm{~g}$ was used to measure the quality of sandstone samples. The sizes of sandstone specimens were measured through a Vernier caliper with an accuracy of $0.02 \mathrm{~mm}$. The probe frequency used for the P-wave velocity test is $50 \mathrm{~Hz}$, and Vaseline is evenly applied on both ends of the sample before the test. Specimens were heat-treated in a TSX1400 muffle furnace whose setting temperature was increased at a rate of $10^{\circ} \mathrm{C} / \mathrm{min}[12,14,19]$ until a maximum temperature of $800^{\circ} \mathrm{C}$ [27]. In order to ensure that the sample is heated evenly, the temperature is kept constant for $30 \mathrm{~min}$ each at $100^{\circ} \mathrm{C}$. The sandstone was heated to $800^{\circ} \mathrm{C}$ and kept at constant temperature for $2 \mathrm{~h}[8,13,20]$. The YAW-2000 test systems were adopted to evaluate the rock mechanical properties, whose loading rate was set at $0.3 \mathrm{~mm} / \mathrm{s}$. A DS5-16B acoustic emission test system was used to monitor the acoustic emissions, and the threshold of the preamplifier in the AE system is $40 \mathrm{~dB}$. Specimens were divided into four groups with three in each group. Group $\mathrm{C}$ was selected as the reference, whose parameters were measured under the natural status. After specimens were heated to $800^{\circ} \mathrm{C}$, the group $\mathrm{N}$ was cooled naturally and the group $\mathrm{W}$ was cooled to $20^{\circ} \mathrm{C}$ by water spraying. The group $\mathrm{R}$ was cooled with evenly sprayed liquid carbon dioxide from a steel cylinder controlled with a pressure relief value until the room temperature was reached. The cooling consumption time was recorded. All specimens were dried naturally indoor before tests.

\section{Test Result and Analysis}

3.1. Density and Longitudinal Wave Velocity. In order to quantitatively analyze the impact of three cooling methods on mechanical properties of the high-temperature sandstone, the ratio between the density reduction after and before cooling is defined as the density attenuation rate $K_{\rho}$ and the ratio between the longitudinal wave velocity reduction after and before cooling is defined as the wave velocity attenuation rate $K_{v}$ [18]. The detailed densities and $K_{p} s$ corresponding to three cooling methods are provided in Table 1.

As demonstrated in Table 1, various degrees of increasement were observed in the density and $K_{\rho}$ in hightemperature sandstone cooled by three different methods. During the heating process, substances with melting points below $800^{\circ} \mathrm{C}$, such as cement and crystal water, were slowly melted, resulting in more cracks in the sandstone and jeopardizing the sandstone quality $[13,16]$. In contrast, based on the average density reduction, the content of fusible substances contained in the sandstone is relatively low, resulting in limited density reduction.

The detailed information of longitudinal wave velocity and $K_{v} s$ corresponding to three cooling methods is provided in Table 2.

As demonstrated in Table 2, various degrees of increasement were observed in the longitudinal wave 


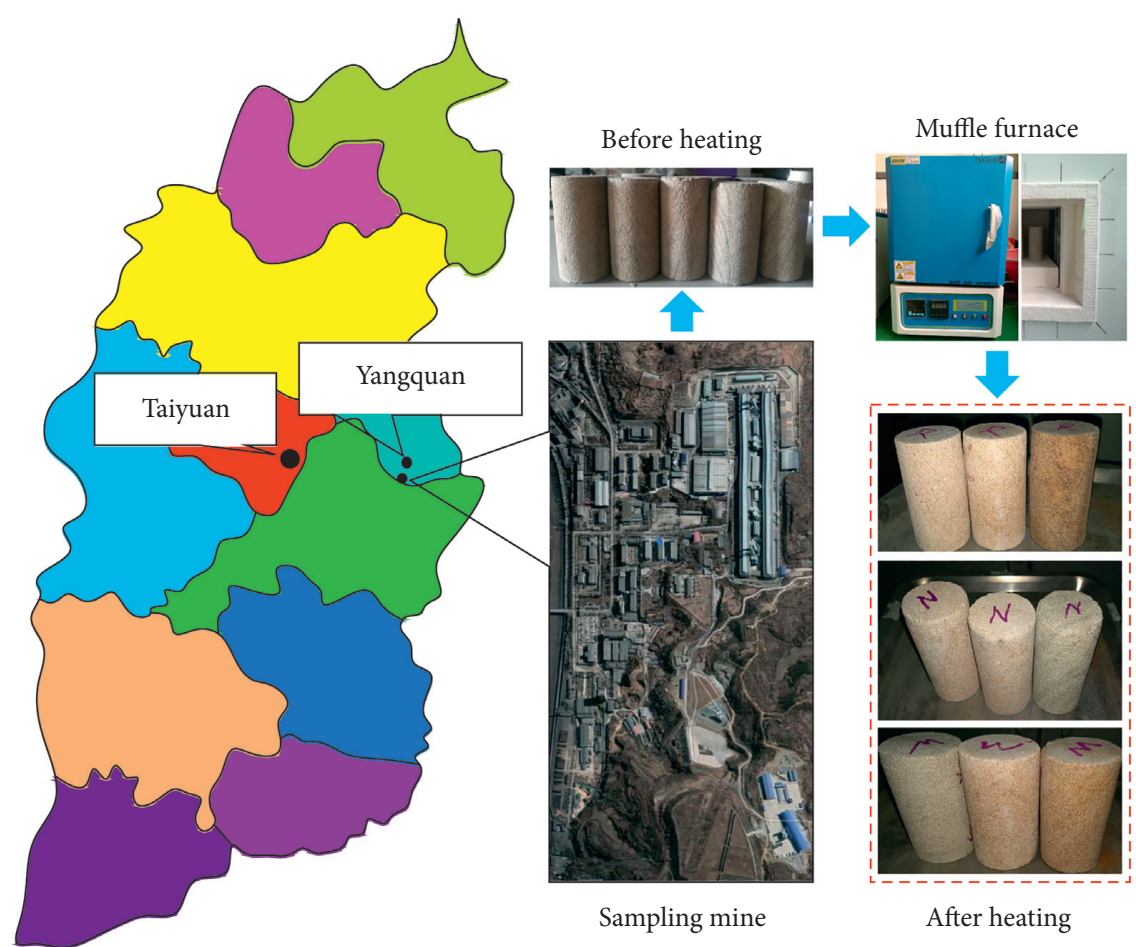

FIgURE 1: Specimen introductions.

Table 1: Density.

\begin{tabular}{|c|c|c|c|c|c|}
\hline & $\begin{array}{l}\text { Density before heating } \\
\left(\mathrm{g} / \mathrm{cm}^{3}\right)\end{array}$ & $\begin{array}{l}\text { Average density before heating } \\
\left(\mathrm{g} / \mathrm{cm}^{3}\right)\end{array}$ & $\begin{array}{l}\text { Density after heating } \\
\left(\mathrm{g} / \mathrm{cm}^{3}\right)\end{array}$ & $\begin{array}{l}\text { Average density after heating } \\
\left(\mathrm{g} / \mathrm{cm}^{3}\right)\end{array}$ & $K_{\rho}(\%)$ \\
\hline \multirow{3}{*}{$\mathrm{C}$} & 2.443 & & - & & \\
\hline & 2.444 & 2.445 & - & - & - \\
\hline & 2.448 & & - & & \\
\hline \multirow{3}{*}{$\mathrm{N}$} & 2.44 & & 2.403 & & \\
\hline & 2.443 & 2.441 & 2.407 & 2.406 & 1.43 \\
\hline & 2.439 & & 2.408 & & \\
\hline \multirow{3}{*}{ W } & 2.438 & & 2.397 & & \\
\hline & 2.439 & 2.439 & 2.398 & 2.398 & 1.68 \\
\hline & 2.44 & & 2.4 & & \\
\hline \multirow{3}{*}{$\mathrm{R}$} & 2.442 & & 2.405 & & \\
\hline & 2.445 & 2.444 & 2.408 & 2.407 & 1.51 \\
\hline & 2.445 & & 2.408 & & \\
\hline
\end{tabular}

TABle 2: Longitudinal wave velocity.

\begin{tabular}{|c|c|c|c|c|c|}
\hline & $\begin{array}{l}\text { Wave velocity before } \\
\text { heating }(\mathrm{km} / \mathrm{s})\end{array}$ & $\begin{array}{c}\text { Average wave velocity before } \\
\text { heating }(\mathrm{km} / \mathrm{s})\end{array}$ & $\begin{array}{c}\text { Wave velocity after } \\
\text { heating }(\mathrm{km} / \mathrm{s})\end{array}$ & $\begin{array}{l}\text { Average wave velocity } \\
\text { after heating }(\mathrm{km} / \mathrm{s})\end{array}$ & $K_{v}(\%)$ \\
\hline \multirow{3}{*}{$\mathrm{C}$} & 3.261 & & - & & \\
\hline & 3.257 & 3.258 & - & - & - \\
\hline & 3.256 & & - & & \\
\hline \multirow{3}{*}{$\mathrm{N}$} & 3.271 & & 1.847 & & \\
\hline & 3.274 & 3.273 & 1.847 & 1.848 & 43.54 \\
\hline & 3.274 & & 1.85 & & \\
\hline \multirow{3}{*}{ W } & 3.168 & & 1.437 & & \\
\hline & 3.171 & 3.169 & 1.438 & 1.436 & 54.69 \\
\hline & 3.168 & & 1.433 & & \\
\hline \multirow{3}{*}{$\mathrm{R}$} & 3.243 & & 1.224 & & \\
\hline & 3.243 & 3.242 & 1.2 & 1.221 & 62.34 \\
\hline & 3.240 & & 1.119 & & \\
\hline
\end{tabular}


velocity and $K_{v}$ in high-temperature sandstone cooled by three different methods. According to the wave velocity test results, comparing with the reference wave velocity obtained under the room temperature, the high-temperature sandstone specimens experienced various levels of reductions in wave velocity with increased $K_{v} . K_{v} s$ measured from the specimens cooled naturally, by water, and by liquid carbon dioxide is $43.54 \%, 54.69 \%$, and $62.34 \%$, respectively. The longitudinal wave velocity indicates the crack developing status inside sandstones, suggesting the internal damage due to different cooling methods. The heat shock produced by the natural cooling, water cooling, and rapid cooling (cooled by liquid carbon dioxide) increased accordingly, resulting in gradually decreasing destructions to the internal structure. In addition, the density attenuation rate (maximum value of $1.68 \%$ ) of specimens is far lower than the wave velocity attenuation rate (maximum value of $62.34 \%$ ).

3.2. Uniaxial Compressive Stress-Strain Behavior. A series of uniaxial compression tests were conducted to the hightemperature sandstones cooled with three different methods. The stress-strain curves were developed based on the test results, as demonstrated in Figure 2.

Comparing with the sandstone under the natural status, the compression sections of the stress-strain curves of the high-temperature sandstone samples treated by three cooling methods are longer, suggesting the crack developed inside the sandstone. Groups N, W, and R demonstrated some gradually longer compression sections of the stressstrain curves, indicating more severe damages. Meanwhile, the drastic turning points occurred after the peak values suggest the characteristics of brittle material demonstrated by the high-temperature sandstone cooled differently.

3.3. Uniaxial Compressive Strength and Young's Modulus. Figures 3(a) and 3(b) and Table 3 show the uniaxial compressive strengths and Young's modulus of high-temperature sandstone cooled differently.

The test results indicate that all cooling methods adopted have caused some reductions in the uniaxial compressive strengths and Young's modulus of sandstone. The average uniaxial compressive strength was decreased from $52.27 \mathrm{MPa}$ to $42.39 \mathrm{MPa}$, by about $18.9 \%$ under the natural cooling. The average uniaxial compressive strength was decreased from $52.27 \mathrm{MPa}$ to $30.80 \mathrm{MPa}$, by about $41.08 \%$ under the water cooling. The average uniaxial compressive strength was decreased from $52.27 \mathrm{MPa}$ to $22.56 \mathrm{MPa}$, by about $56.84 \%$ under the rapid cooling (cooled by liquid carbon dioxide). In terms of Young's modulus, comparing with the reference group $\mathrm{C}$, groups $\mathrm{N}, \mathrm{W}$, and $\mathrm{R}$ demonstrated a reduction of $33.88 \%, 48.21 \%$, and $61.16 \%$, respectively, which is consistent with the trend of the uniaxial compressive strength. Compared with the results of uniaxial compressive strength and Young's modulus shown in Figures 3(a) and 3(b) $[19,28,29]$, the experiment demonstrated a similar trend. Based on uniaxial compressive strength and Young's modulus, various cooling methods were ranked as follows: sample cooled by liquid carbon

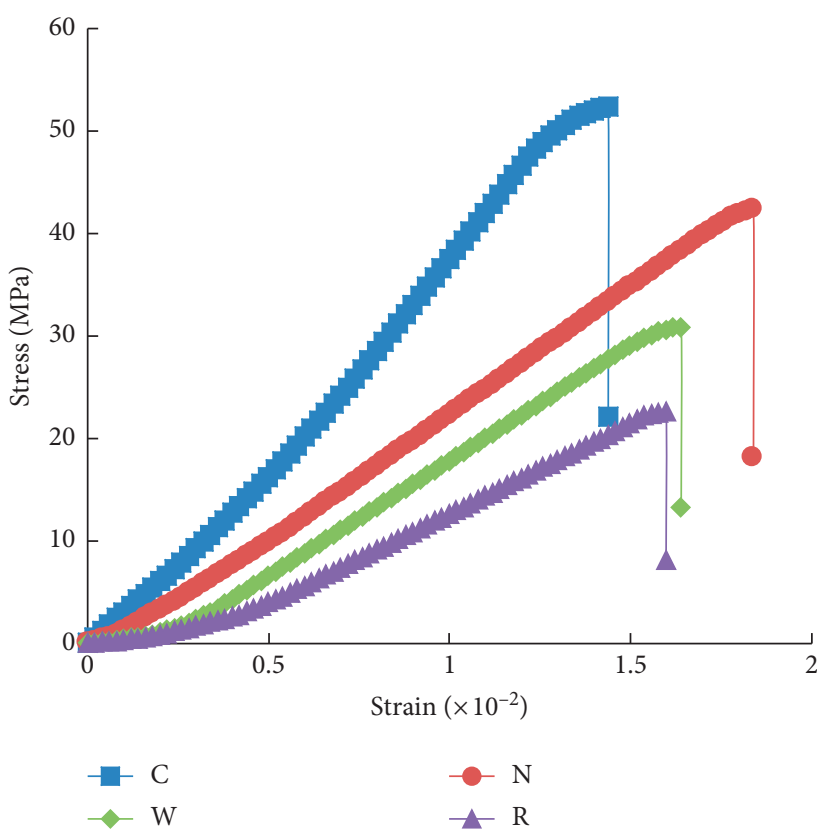

FIgURE 2: Stress-strain curve.

dioxide $<$ sample cooled by water $<$ sample cooled natural$l y<$ the sample under natural status.

Both types of tests indicate that the cooling method has a meaningful impact on the thermal shock, which is the major trigger of internal damage in sandstone. Therefore, in order to ensure the safety and service life of underground facilities, oxygen isolation or other equivalent fire extinguishing methods should be preferred during the fire rescue to minimize the internal damage to sandstone.

3.4. Acoustic Emission Characteristics. Acoustic emission and spectrum signature can provide insightful indications of the dynamic development inside the rocks, which are widely adopted in the analysis of rock mechanical properties. Figure 4 provides the acoustic emission trends of groups $\mathrm{C} 2$, N1, W2, and R1 to demonstrate different levels of damages caused by three cooling methods to the high-temperature sandstone specimens.

According to Figure 4, the acoustic emission was zero or close to zero under three cooling methods. The initial cracks started to close at the stage of compression without any new damage development. As the axial stress increased, before reaching the peak, the acoustic emission increased drastically, suggesting the intensive development of cracks inside the sandstone specimens. The cracks continued to develop until rupture. Therefore, the frequency of acoustic emission can be viewed as a damage level indicator for test specimens.

Reviewing the distribution of acoustic emission under three cooling methods, the acoustic emission distributions of specimens N1, W2, and R1 are wider than specimen C2, suggesting that the progressive fracture stage of the specimen subject to high temperature and subsequent cooling is longer. Comparing four groups of specimens, the acoustic emission occurred earliest in the reference specimens, 


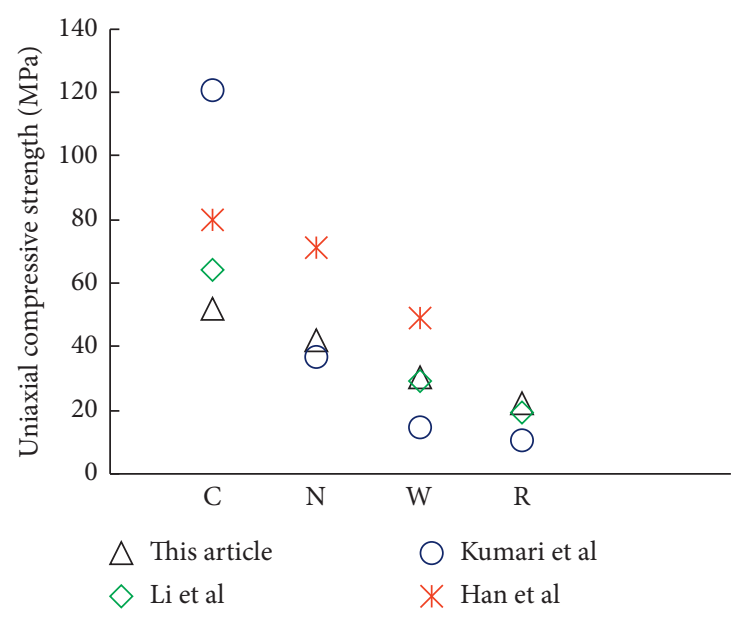

(a)

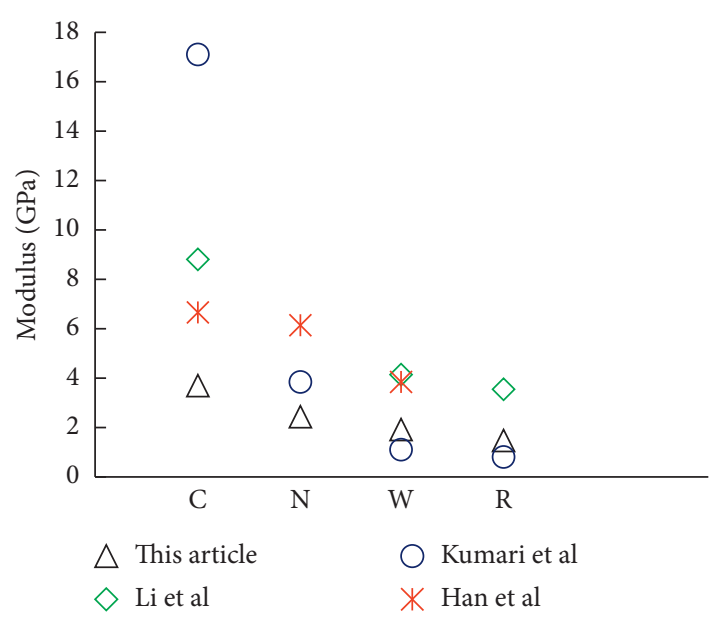

(b)

FIGURE 3: Ratio between strength and Young's modulus [19, 28, 29].

TABLE 3: Uniaxial compressive strength and Young's modulus.

\begin{tabular}{|c|c|c|c|c|}
\hline & Uniaxial compressive strength $(\mathrm{MPa})$ & Average (MPa) & Young's modulus (GPa) & Average (GPa) \\
\hline \multirow{3}{*}{$\mathrm{C}$} & 53.25 & & 3.49 & \\
\hline & 52.3 & 52.27 & 3.65 & 3.63 \\
\hline & 51.26 & & 3.75 & \\
\hline \multirow{3}{*}{$\mathrm{N}$} & 42.3 & & 2.56 & \\
\hline & 42.2 & 42.39 & 2.2 & 2.3 \\
\hline & 42.67 & & 2.44 & \\
\hline \multirow{3}{*}{$\mathrm{W}$} & 31.81 & & 1.98 & \\
\hline & 30.94 & 30.8 & 1.96 & 1.88 \\
\hline & 29.65 & & 1.71 & \\
\hline \multirow{3}{*}{$\mathrm{R}$} & 22.58 & & 1.27 & \\
\hline & 21.54 & 22.56 & 1.59 & 1.41 \\
\hline & 23.56 & & 1.36 & \\
\hline
\end{tabular}

followed by rapid-cooled specimens (cooled by liquid carbon dioxide), water-cooled specimens, and naturally cooled specimens. However, comparing with other groups of specimens (N-465s, W2-415s, and R1-405s), less time was consumed by the reference group from the initial loading to the rupture (288s), which indicates that the reference group was the last one to generate acoustic emission. After cooling, different levels of damages were produced, resulting in various numbers of cracks. The cracks not only jeopardize the strengths of specimens but also cause surface shedding, which are captured by the acoustic emission devices. The numbers of cracks due to three cooling methods impact the occurrence timings of the acoustic emissions in different groups of specimens. Early occurrences of the acoustic emission indicate more severe damage inside the sandstone. Among three cooling methods, based on the occurrence timings of the acoustic emission, the rapid cooling method (cooled by liquid carbon dioxide) produced the most severe damage, followed by the water cooling method and the natural cooling method.

In terms of morphology, the color of specimens transited from greyish white into light brownish red after the heat. The damages observed in the reference group and specimens cooled naturally were defined as the shear damage. Limited tensile cracks were observed in the specimens cooled by water and liquid carbon dioxide along with the shear damage, suggesting that more intensive thermal shocks were produced under the water cooling method and the rapid cooling method (cooled by liquid carbon dioxide) and weak planes featured with multiple orientations were formed inside.

As shown in Figure 5, the longitudinal compression tensile failure (W1 and R2) and the burst crushing failure (R3) were also observed in the specimens cooled by water and liquid carbon dioxide. Due to the influence of the internal structure and the heterogeneity of sandstone, the density and quantity of fractures produced during cooling in the high-temperature sandstone vary. Similarly, the directions of fractures are different, as well as the fracture joints. Therefore, the failure mode of the sandstone specimen with high-temperature thermal damage during the process of compression deformation is featured with significant randomness, which is not necessarily related to the cooling mode. Ruptures are more likely to occur during the uniaxial 


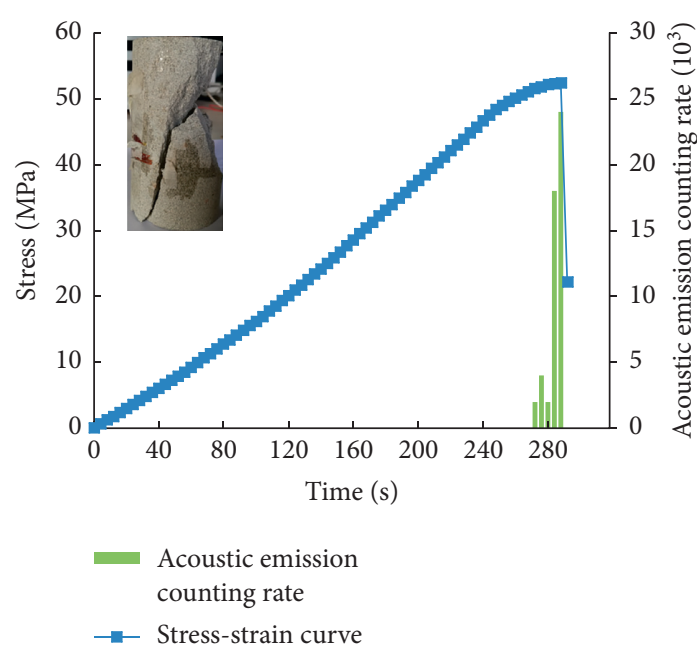

(a)

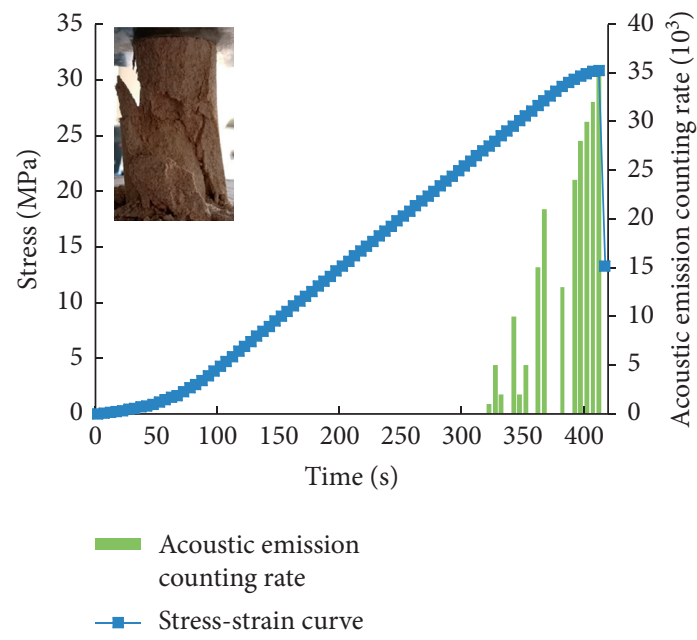

(c)

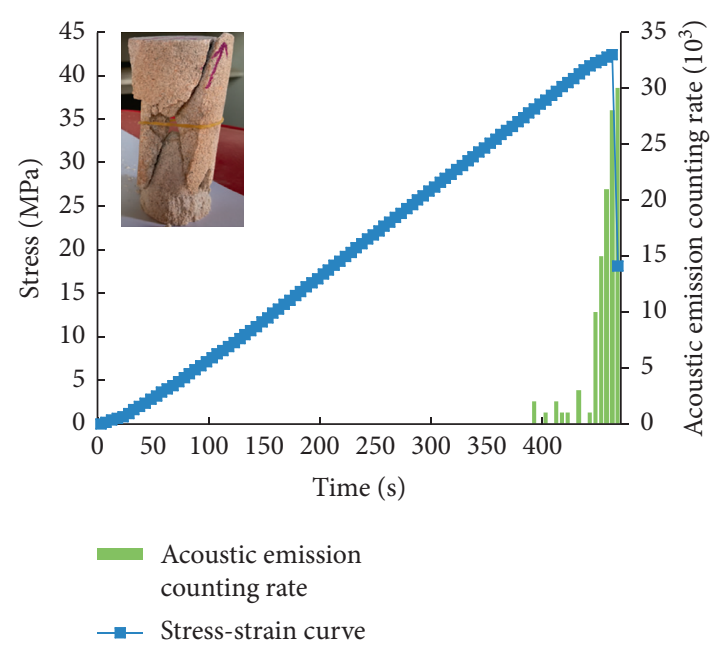

(b)

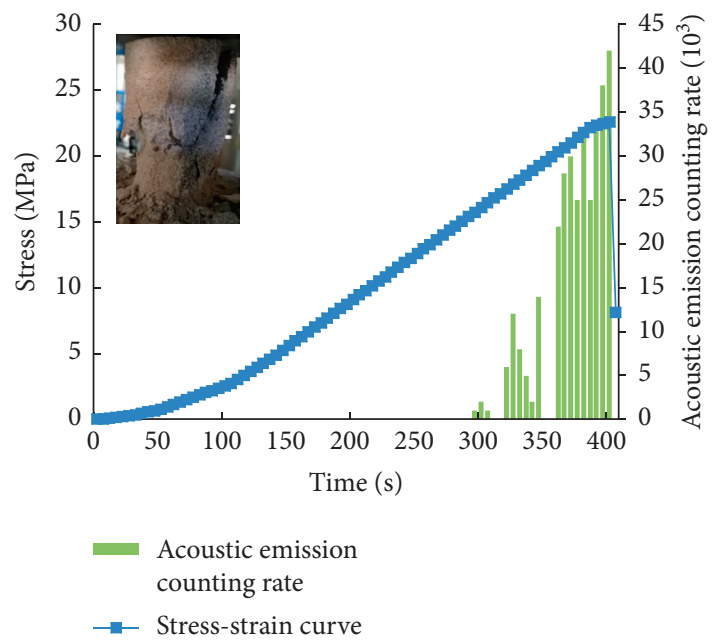

(d)

Figure 4: Acoustic emission response and damage. (a) C2. (b) N1. (c) W2. (d) R1.

compression tests along the weak planes, resulting in shear or tensile damage. It is not surprising that some specimens demonstrated both shear and tensile damage simultaneously. Taken together, the water cooling and rapid cooling (cooled by liquid carbon dioxide) methods tend to induce more internal cracks and tensile failures. In addition, comparing with the reference group, the thermal shocks reduced the strengths of group $\mathrm{N}, \mathrm{W}$, and $\mathrm{R}$ specimens due to the formation of weak planes inside.

\section{The Discussion of Cooling Rate}

As discussed previously, different cooling methods produce various cooling rates. Therefore, establishing the relationship between the rock parameter changes and the cooling rates is critical to evaluate the impact of various cooling methods on the high-temperature sandstone.

The changes to the density attenuation rate and the longitudinal wave velocity attenuation rate responding to various cooling rates are presented in Figure 6 . The cooling rate of the heated rock is a calculated parameter obtained by dividing the temperature decrease by the cooling time. The surface temperature of the specimen was measured by the infrared thermometer continuously until the specimen was cooled to $40^{\circ} \mathrm{C} \pm 5^{\circ} \mathrm{C}$. An infrared thermometer with an accuracy of $0.1^{\circ} \mathrm{C}$ was fixed at a specific position to test the surface temperature of a certain point of the rock specimen until the temperature of the specimen drops to $40^{\circ} \mathrm{C} \pm 5^{\circ} \mathrm{C}$ and the cooling time was recorded. If the difference between the test results within 5 minutes is less than $0.5^{\circ} \mathrm{C}$, the temperature of the test piece is considered to be stable.

The functional relationship between the density attenuation rate $K_{\rho}$ and the cooling rate, the longitudinal wave velocity attenuation rate $K_{v}$ and the cooling rate are developed and presented in equations (1) and (2), respectively:

$$
\begin{aligned}
& K_{\rho}=-0.00008 c^{2}+0.001 c+0.0139\left(R^{2}=1\right), \\
& K_{v}=0.0183 c+0.4347\left(R^{2}=0.9827\right),
\end{aligned}
$$

where $c$ refers to the cooling rate at ${ }^{\circ} \mathrm{C} / \mathrm{s}$. 


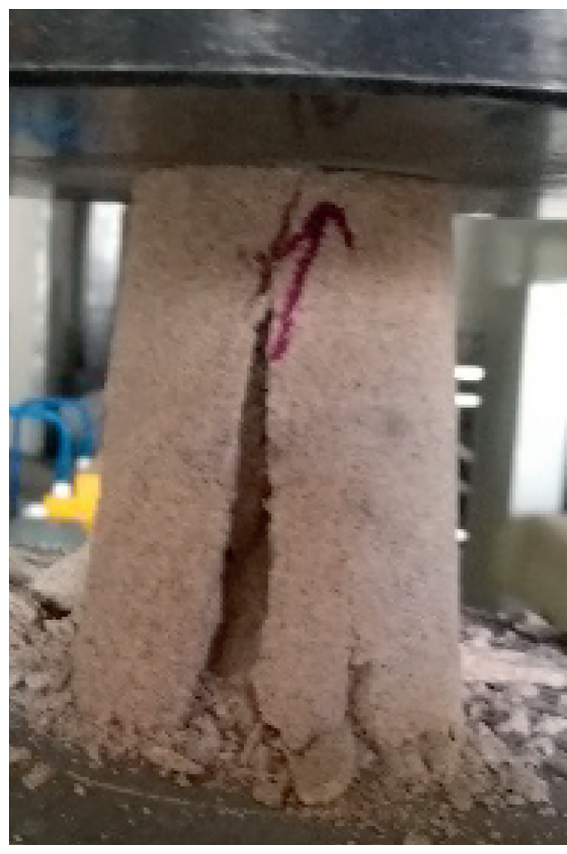

(a)

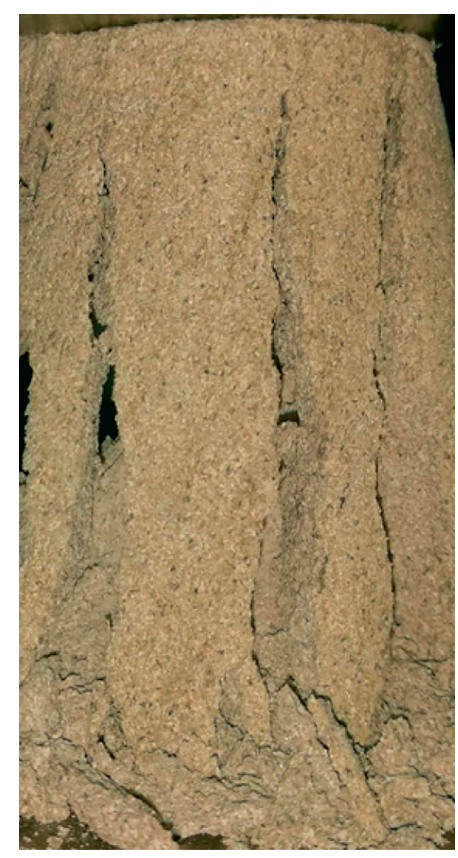

(b)

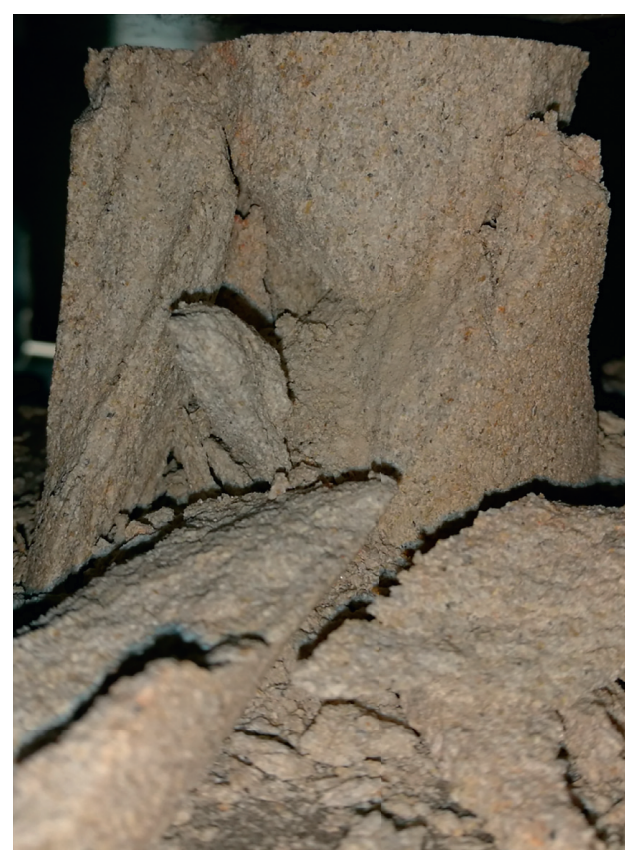

(c)

Figure 5: Damage form of (a) W1, (b) R2, and (c) R3.

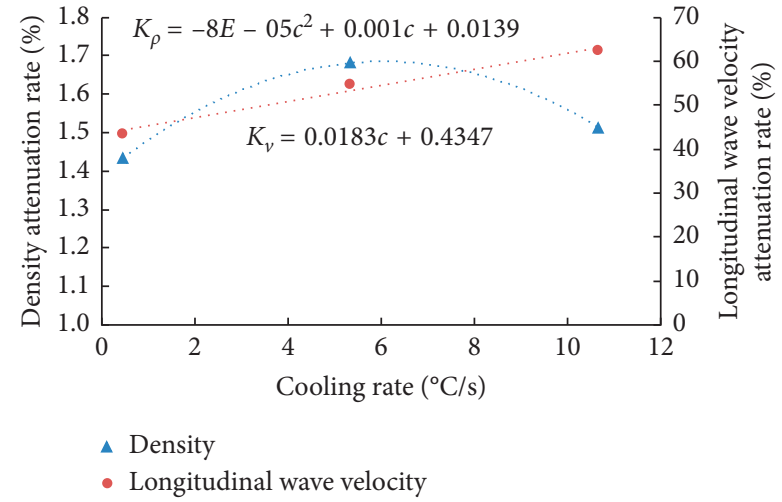

FIgURE 6: The relationship between the density attenuation rate, the longitudinal wave velocity attenuation rate, and the cooling rate.

The functional relationship between the density attenuation rate $K_{\rho}$ and the cooling rate is constructed in the form of polynomial, while the functional relationship between the longitudinal wave velocity attenuation rate $K_{v}$ and the cooling rate is constructed in the form of a linear equation. Further analysis and more parameters are required to characterize the damages in rocks due to various cooling rates.

The cooling rate exerts a significant impact on the underground facility safety and service life. Under the assumption that the ratio between the strength reduction after and before cooling is defined as the strength attenuation rate $K_{s}$ and Young's modulus reduction after and before cooling is defined as Young's modulus attenuation rate $K_{e}$, the strength attenuation rate and Young's modulus attenuation rate responding to various cooling rates are presented in Figure 7.

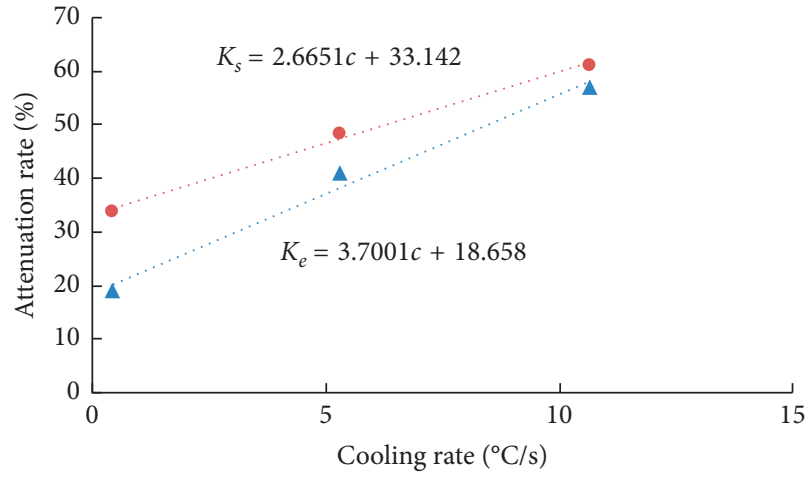

- Stress
- Modulus

FIGURE 7: The relationship between the strength attenuation rate, Young's modulus attenuation rate, and the cooling rate.

As Figure 7 demonstrates, the cooling rates increased, respectively, under the rapid cooling method (cooled by liquid carbon dioxide), the water cooling method, and the natural cooling method. A higher level of thermal shock produces more tensile stress and more severe internal damage along with more macro cracks, resulting in the decrease in the cohesion force and the lowering of internal friction angles. The compressive strength and Young's modulus deteriorate consequently. The impact of various cooling methods on the high-temperature sandstone originates from different cooling rates. Among three cooling methods, the rapid cooling method (cooled by liquid carbon dioxide) provides the highest cooling rate, resulting in the highest thermal shock and tensile stress, as well as the most 
severe damage including the reduction in rock strength and Young's modulus.

The functional relationships between the strength attenuation rate $K_{s}$ and the cooling rate, Young's modulus attenuation rate $K_{e}$ and the cooling rate are developed and presented in equations (3) and (4), respectively:

$$
\begin{aligned}
& K_{s}=3.7001 c+18.658\left(R^{2}=0.9851\right), \\
& K_{e}=2.6651 c+33.142\left(R^{2}=0.9971\right) .
\end{aligned}
$$

Generally, the functional relationship between the density attenuation rate $K_{\rho}$ and the cooling rate is constructed in the form of polynomial, which is different from the linear equations (such as the functional relationship between the longitudinal wave velocity attenuation rate $K_{v}$ and the cooling rate, the functional relationship between the strength attenuation rate attenuation rate $K_{s}$ and the cooling rate, and the functional relationship between Young's modulus attenuation rate $K_{e}$ and the cooling rate). Although the rapid cooling method (cooled by liquid carbon dioxide) causes more serious damage to the high-temperature sandstone specimens, the specimens cooled by water suffered with more quality loss and higher density attenuation rate due to the scouring effect of water flow. Therefore, the density attenuation rate $K_{\rho}$ is not suitable to characterize the damage of the high-temperature sandstone specimen caused by different cooling rates. The longitudinal wave velocity attenuation rate $K_{v}$, the strength attenuation rate attenuation rate $K_{s}$, and Young's modulus attenuation rate $K_{e}$ could be used as the damage characterization index.

It is worth mentioning that this study also provides some insightful references to the rock breaking process. During the excavations of underground projects, hard rocks are often encountered. Rock blasting sometimes is used to remove the hard rocks. However, many restrictions apply to the rock blasting such as the safety concerns due to the gas explosion and smoke removal afterwards. Many experts have proposed effective alternatives to rock blasting such as the microwave technology, the ultrasound technology, and the liquid nitrogen cooling. Rock is a brittle material, indicating that the harder rock demonstrates a higher brittleness. When rocks are heated and cooled rapidly, rocks can be broken easily by taking advantage of stresses generated due to the temperature differences. The detailed application needs more research.

\section{Conclusion}

(1) The increase in both the density attenuation rate and the longitudinal wave velocity attenuation rate is observed in high-temperature sandstones under three cooling methods. The rapid cooling method (cooled by liquid carbon dioxide) produces the highest increasement of the density attenuation rate and the longitudinal wave velocity attenuation rate, followed by the water cooling method and the natural cooling method. The overall increasement of the density attenuation rate is relatively limited, comparing with the drastic increasement of the longitudinal wave velocity attenuation rate.

(2) Comparing with the sandstone under the natural status, the compression sections of the stress-strain curves of the high-temperature sandstone samples treated by three cooling methods are longer with lower strain peak values. The uniaxial compressive strength and Young's modulus are reduced as well. The rapid cooling method (cooled by liquid carbon dioxide) produces the highest reduction, followed by the water cooling method and the natural cooling method. Based on the acoustic emission, three cooling methods are ranked as follows: sample cooled by liquid carbon dioxide < sample cooled by water $<$ sample cooled naturally $<$ the sample under natural status, which suggests that the rapid cooling method (cooled by liquid carbon dioxide) produces the most severe damage to the sample, followed by the water cooling method and the natural cooling method.

(3) Only shear damage is observed in the reference group and the specimen group cooled naturally while both shear damage and tensile damage are identified in specimens cooled by water and liquid carbon dioxide.

(4) The functional relationship reflecting the synthesized strength weakening coefficient and the cooling rate provides some insightful references to the following up tests and rock blasting procedures taking advantage of stresses caused by the temperature difference in the future.

\section{Data Availability}

The data used to support the findings of this study are available from the corresponding author upon request.

\section{Conflicts of Interest}

The authors declare that there are no conflicts of interest regarding the publication of this paper.

\section{Acknowledgments}

This work was supported by the Fundamental Research Funds for the Central Universities (Grant no. ZY20200203), Key Laboratory of Building Collapse Mechanism and Disaster Prevention, China Earthquake Administration (Grant no. FZ201207), and Self-financing Project of Scientific Research and Development Plan of Langfang Science and Technology Bureau (Grant no. 2020013046).

\section{References}

[1] H. P. Xie, M. Z. Gao, J. Z. Liu et al., "Research on exploitation and volume estimation of underground space in coal mines," Journal of China Coal Society, vol. 43, no. 6, pp. 1487-1503, 2018, in Chinese. 
[2] J. W. Wu and S. P. Chen, "Effect of heating and cooling on thermal cracking of granite under unconstrained conditions," Chinese Journal of Underground Space and Engineering, vol. 15, no. 1, pp. 108-115, 2019, in Chinese.

[3] C.-b. Yan, "Blasting cumulative damage effects of underground engineering rock mass based on sonic wave measurement," Journal of Central South University of Technology, vol. 14, no. 2, pp. 230-235, 2007.

[4] G. Hu, H. L. Fei, S. J. Bao, and Z. G. Yang, "Blasting damage accumulative effect of tunnel surrounding rock structure on HHT," Chinese Journal of Underground Space and Engineering, vol. 16, no. 1, pp. 249-259, 2020, in Chinese.

[5] X. Liu, P. Yan, W. B. Lu et al., "Effects of the high in-situ stress level on the acoustic detection and the damage degree evaluation of the excavation damage zone," Advance Engineering Science, vol. 51, no. 6, pp. 115-123, 2019, in Chinese.

[6] Z. M. Jiang, S. Z. Qin, and D. Tang, "Numerical study on accumulative damage characteristics of underground rock caverns for compressed air energy storage," Chinese Journal of Geotechnical Engineering, vol. 42, no. 2, pp. 230-238, 2020, in Chinese.

[7] Y. S. Luo, B. Dou, H. Tian, J. Chen, P. Xiao, and S. T. Zhang, "Comparative experimental study on physical and mechanical properties of granite after natural cooling and under real-time high temperature," Earth Science Frontiers, vol. 27, no. 1, pp. 178-184, 2020, in Chinese.

[8] Y. L. Zhu, J. Yu, H. D. Gao, G. Li, X. Q. Zhou, and X. Q. Zheng, "Effect of water cooling on microscopic damage and dynamic properties of high-temperature granite," Explosion and Shock Waves, vol. 39, no. 8, pp. 84-95, 2019, in Chinese.

[9] C. I. McDermott, A. R. L. Randriamanjatosoa, H. Tenzer, and O. Kolditz, "Simulation of heat extraction from crystalline rocks: the influence of coupled processes on differential reservoir cooling," Geothermics, vol. 35, no. 3, pp. 321-344, 2006.

[10] L. N. Yang, Z. Q. Jiang, W. Q. Zhang, and J. S. Geng, "Mechanical properties of sandstone after high temperature," China Earthquake Engineering Journal, vol. 38, no. 2, pp. 299-302, 2016, in Chinese.

[11] H. J. Su, H. W. Jing, H. H. Zhao, and Q. Yin, "Study on tensile strength and size effect of red sandstone after high temperature treatment," Chinese Journal of Rock Mechanics and Engineering, vol. 34, no. S1, pp. 2879-2887, 2015, in Chinese.

[12] C. B. Xu and H. S. Zhou, "Test investigation of triaxial compressive strength of coarse sandstone after high temperature," Chinese Journal of Rock Mechanics and Engineering, vol. 35, no. S1, pp. 2811-2818, 2016, in Chinese.

[13] Y. Y. Zhao, K. Wei, J. Q. Zhou, X. Li, and Y. F. Chen, "Laboratory study and micromechanical analysis of mechanical behaviors of three thermally damaged rocks," Chinese Journal of Rock Mechanics and Engineering, vol. 36, no. 1, pp. 142-151, 2017, in Chinese.

[14] D. Hou and J. Peng, "Triaxial mechanical behavior and strength model for thermally-damaged marble," Chinese Journal of Rock Mechanics and Engineering, vol. 38, no. S1, pp. 2603-2613, 2019, in Chinese.

[15] B. P. Xi, Y. C. Wu, Y. S. Zhao, L. Wang, B. P. Zhang, and X. M. Niu, "Experimental investigations of compressive strength and thermal damage capacity characterization of granite under different cooling modes," Chinese Journal of Rock Mechanics and Engineering, vol. 39, no. 2, pp. 286-300, 2020, in Chinese.

[16] Z. P. Huang, Y. Zhang, and W. D. Wu, "Analysis of mechanical and wave properties of heat-treated marble by water cooling," Rock and Soil Mechanics, vol. 37, no. 2, pp. 367-375, 2016, in Chinese.

[17] Z. P. Huang, Y. Zhang, Y. K. Sun, C. Y. Liu, and W. D. Wu, "Mechanical and acoustic characteristics of high temperature limestone with water cooling treatment," Journal of Central South University (Science and Technology), vol. 47, no. 12, pp. 4181-4189, 2016, in Chinese.

[18] Z. W. Huang, H. T. Wen, X. G. Wu et al., "Experimental study on cracking of high temperature granite using liquid nitrogen," Journal of China University of Petroleum, vol. 43, no. 2, pp. 68-76, 2019, in Chinese.

[19] G. S. Han, H. W. Jing, H. J. Su, Q. Yin, J. Y. Wu, and Y. Gao, "Experimental research on mechanical behaviors of watercooled sandstone after high temperature treatment," Journal of China University of Mining and Technology, vol. 49, no. 1, pp. 69-75, 2020, in Chinese.

[20] P. H. Jin, Y. Q. Hu, J. X. Shao, G. K. Zhao, X. Z. Zhu, and C. Li, "Experimental study on physical mechanical and transport properties of granite subjected to rapid cooling," Chinese Journal of Rock Mechanics and Engineering, vol. 37, no. 11, pp. 2556-2564, 2018, in Chinese.

[21] Y.-J. Shen, X. Hou, J.-Q. Yuan, and C.-H. Zhao, "Experimental study on temperature change and crack expansion of high temperature granite under different cooling shock treatments," Energies, vol. 12, no. 11, p. 2097, 2019.

[22] Y. J. Shen, X. Hou, J. Q. Yuan, S. F. Wang, and C. H. Zhao, "Thermal cracking characteristics of high-temperature granite suffering from different cooling shocks," International Journal of Fracture, 2020.

[23] Y. Shen, X. Hou, J. Yuan et al., "Thermal deterioration of hightemperature granite after cooling shock: multiple-identification and damage mechanism," Bulletin of Engineering Geology and the Environment, 2020.

[24] B. Isaka, R. Gamage, T. Rathnaweera, M. Perera, D. Chandrasekharam, and W. Kumari, "An influence of thermally-induced micro-cracking under cooling treatments: mechanical characteristics of Australian granite," Energies, vol. 11, no. 6, p. 1338, 2018.

[25] M. Hosseini, "Effect of temperature as well as heating and cooling cycles on rock properties," Journal of Mining Environment, vol. 8, no. 4, pp. 631-644, 2017.

[26] R. Li, Z. Huang, X. Wu, P. Yan, and X. Dai, "Cryogenic quenching of rock using liquid nitrogen as a coolant: investigation of surface effects," International Journal of Heat and Mass Transfer, vol. 119, no. 4, pp. 446-459, 2018.

[27] Z. G. Yan, Q. X. Yang, and H. H. Zhu, "Experimental study on fire in Qinling extra-long highway tunnel," China Civil Engineering Journal, vol. 11, pp. 96-101, 2005.

[28] Q. Li, T. Yin, X. Li, and S. Zhang, "Effects of rapid cooling treatment on heated sandstone: a comparison between water and liquid nitrogen cooling," Bulletin of Engineering Geology and the Environment, vol. 79, no. 1, pp. 313-327, 2020.

[29] W. G. P. Kumari, P. G. Ranjith, M. S. A. Perera, B. K. Chen, and I. M. Abdulagatov, "Temperature-dependent mechanical behaviour of Australian Strathbogie granite with different cooling treatments," Engineering Geology, vol. 229, pp. 31-44, 2017. 